\title{
Laparoscopic Treatment of Recurrent and Chemoresistant Cesarean Scar Choriocarcinoma
}

mehmet bakır ${ }^{1}$, Ozer Birge ${ }^{2}$, Ceyda Karadağ ${ }^{1}$, selen doğan ${ }^{3}$, and tayup simsek ${ }^{3}$

${ }^{1}$ Affiliation not available

${ }^{2}$ Sudan Nyala-Turkey Hospital

${ }^{3}$ Akdeniz University Medical School

September 29, 2020

\begin{abstract}
We also aimed to present our experience about the diagnosis and treatment of our cesarean scar choriocarcinoma case whose tumor was chemoresistant and recurred in four months.
\end{abstract}

\section{Hosted file}

revised manuscript.pdf available at https://authorea.com/users/337483/articles/483787laparoscopic-treatment-of-recurrent-and-chemoresistant-cesarean-scar-choriocarcinoma

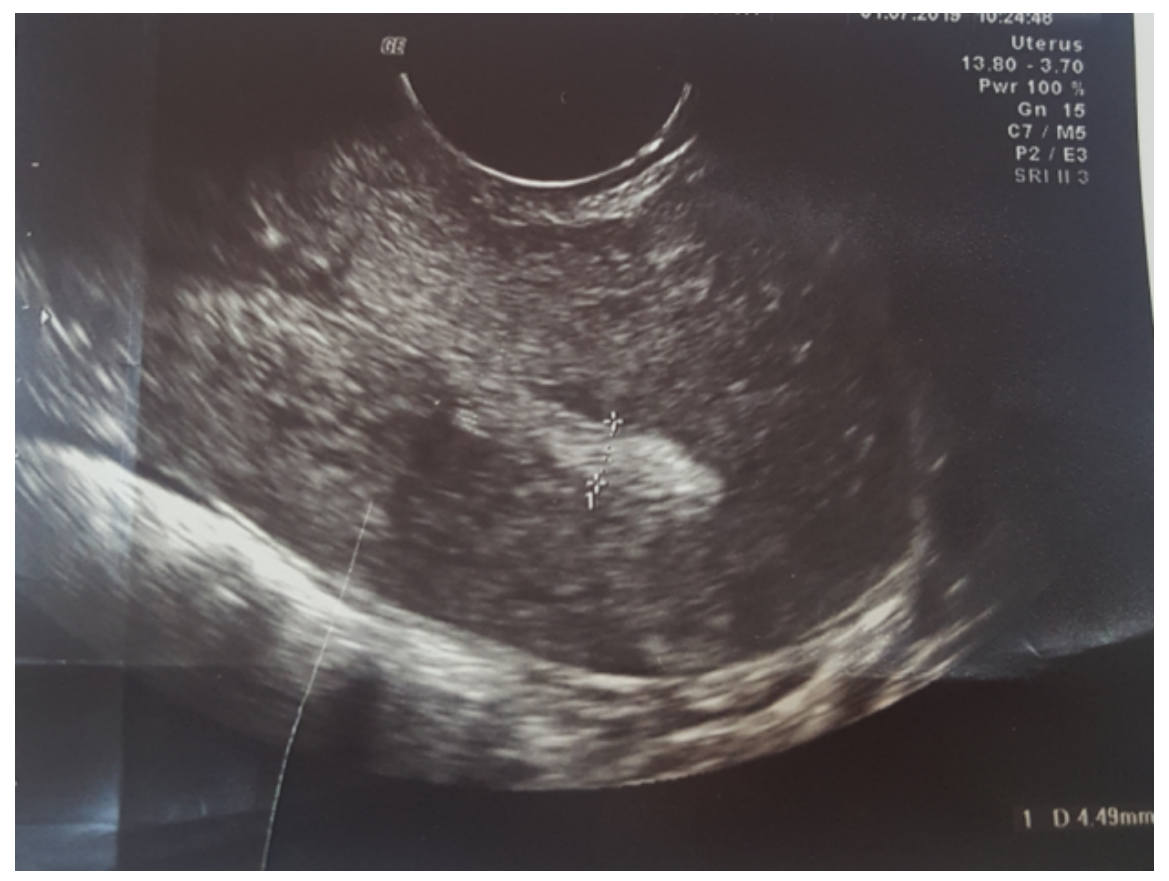




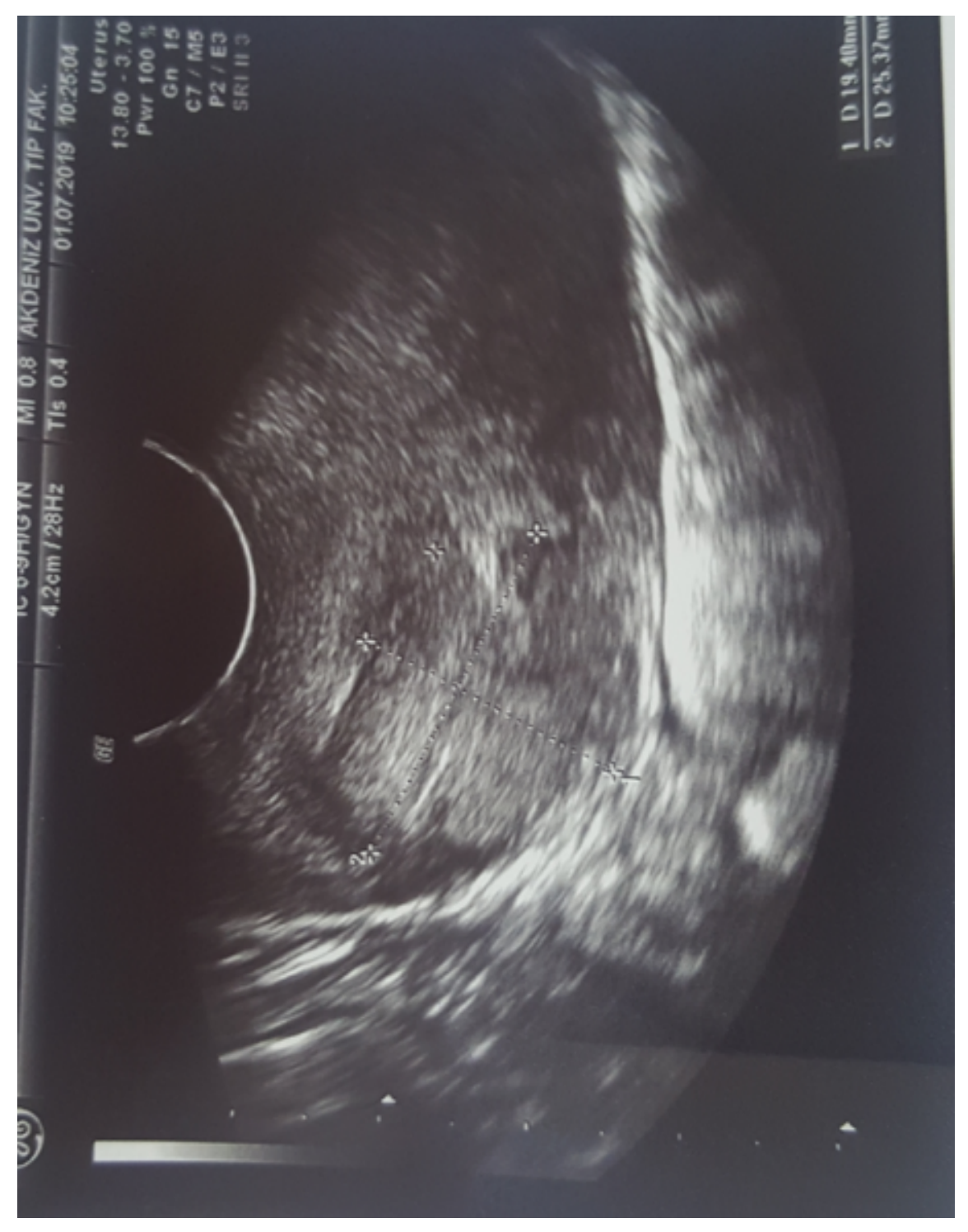



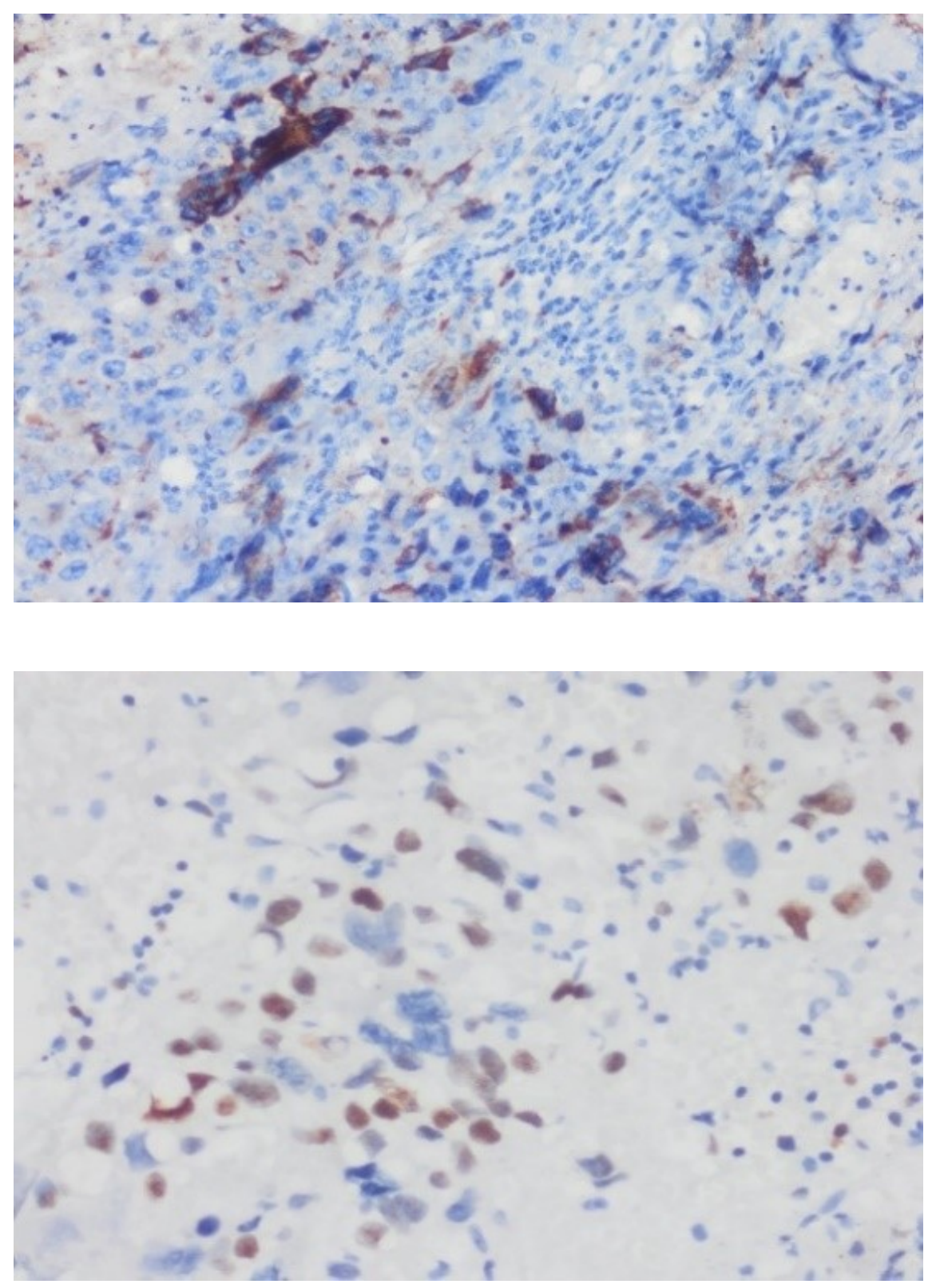

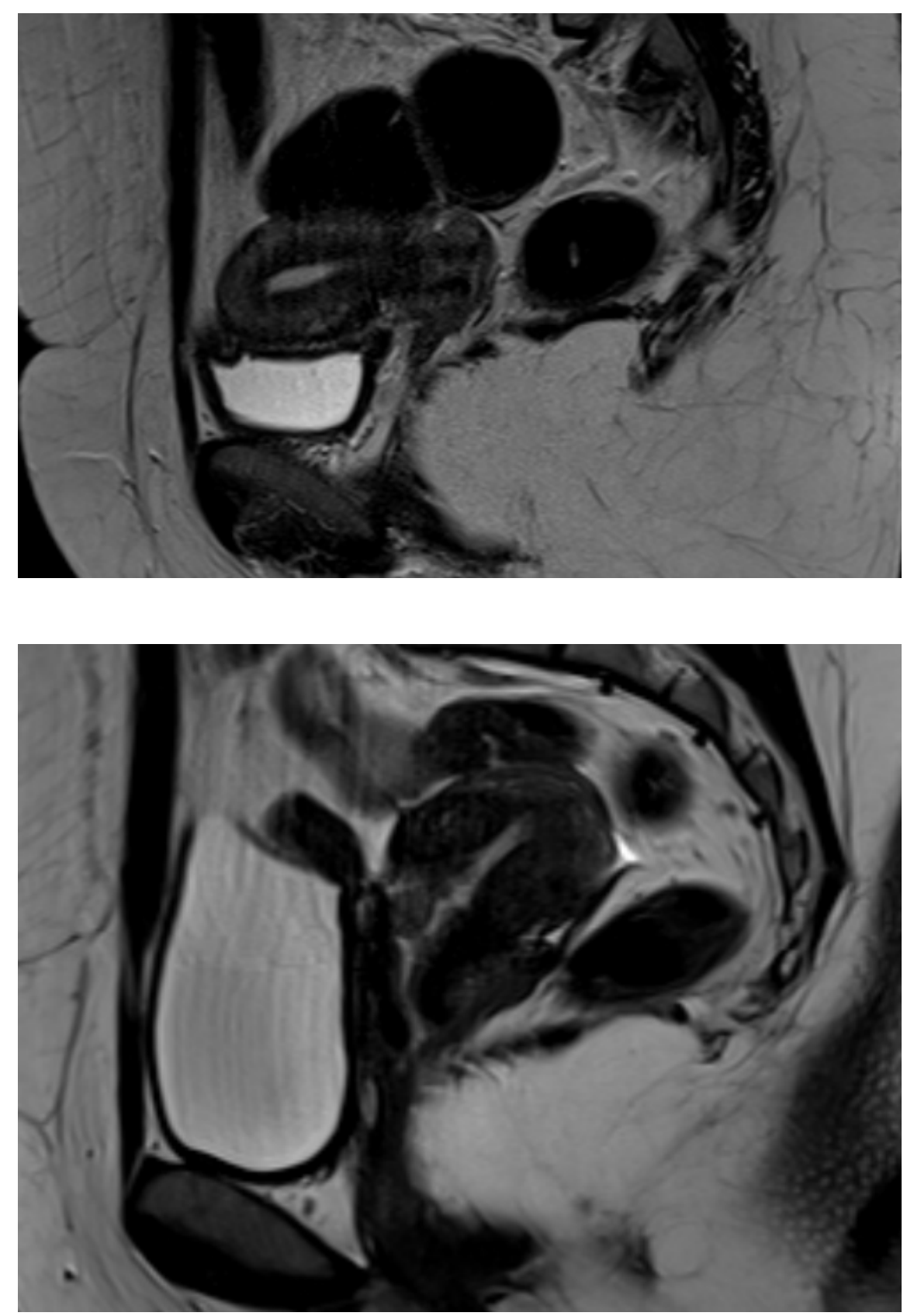

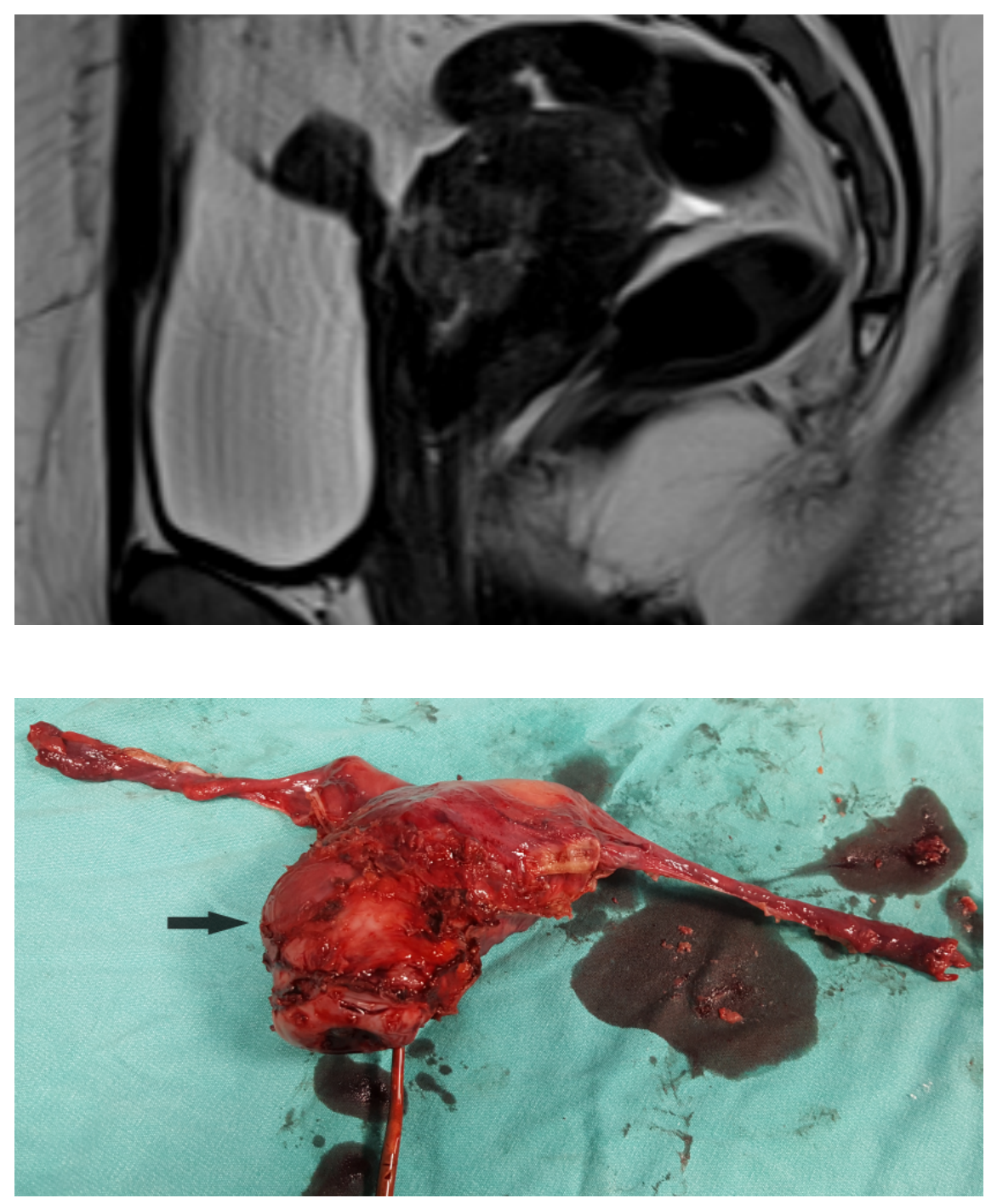